\title{
A unidimensionalização da linguagem e a fragilização teórica do campo investigativo educacional: desafios para a pesquisa em educação
}

Vivian Baroni*

\begin{abstract}
Resumo: Tendo por base o conceito marcuseano de linguagem unidimensional, o presente ensaio pretende problematizar esse tema com relação às suas implicações no campo da pesquisa educacional. A não utilização do conceito e do excesso de significado que a linguagem bidimensional traz em si, resulta na fragilidade teórica fortemente sentida no campo da pesquisa educacional, que resulta, em última instância, na dificuldade de validação do seu conhecimento. Nesse sentido, defendemos a importância da retomada dos estudos de caráter teórico, assim como do trabalho adequado do conceito e dos universais, como instrumentos conceituais imprescindíveis na pesquisa que deseja considerar toda a complexidade do campo da educação.
\end{abstract}

Palavras chave: linguagem unidimensional; pesquisa educacional; teoria; empiria; formação.

The unidimensionalization of language and the theoretical fragilization of the educational investigative field: challenges for research in education

\begin{abstract}
Based on the Marcusean concept of unidimensional language, the present essay intends to problematize this theme in relation to its implications in the field of educational research. The non-use of the concept and the excess of meaning that the two-dimensional language brings in itself results in the theoretical fragility strongly felt in the field of educational research, which results,

* Doutoranda em Educação na Universidade de Passo Fundo (UPF). Atualmente desenvolve pesquisas ligadas à Educação estética em Herbert Marcuse e Friedrich Schiller. E-mail:vivianbaroni@hotmail.com ORCID: https://orcid.org/0000-0002-1280-1388 Apoio/Financiamento: PROSUC/CAPES
\end{abstract}


A unidimensionalização da linguagem e a fragilização teórica do campo investigativo educacional: desafios para a pesquisa em educação

in the last instance, the difficulty of validating its knowledge. In this sense, we defend the importance of resuming theoretical studies, as well as the adequate work of the concept and the universals, as essential conceptual instruments in the research that wishes to consider all the complexity of the field of education.

Keywords: one-dimensional language; educational research; theory; empiria; formation.

\section{Unidimensionalización del lenguaje y fragilización teórica del campo de investigación educativa: desafíos para la investigación educativa}

Resumen: Basado en el concepto marcusiano de lenguaje unidimensional, el presente ensayo pretende problematizar este tema en relación con sus implicaciones en el campo de la investigación educativa. La falta de uso del concepto y el exceso de significado que el lenguaje bidimensional trae consigo resulta en la debilidad teórica que se siente fuertemente en el campo de la investigación educativa, lo que en última instancia resulta la dificultad de validar su conocimiento. En este sentido, defendemos la importancia de la reanudación de los estudios teóricos, así como el trabajo adecuado del concepto y los universales, como instrumentos conceptuales indispensables en la investigación que desea considerar toda la complejidad del campo de la educación.

Palabras clave: lenguaje unidimensional; investigación educativa; teoría empirismo formación.

\section{Considerações iniciais}

Nas últimas décadas, os pesquisadores em educação vêm acompanhando com apreensão a diminuição crescente de estudos mais sólidos no âmbito teórico e, na mesma medida, o aumento das pesquisas empíricas. O que causa preocupação é que uma parte considerável dessas pesquisas empíricas segue um modelo epistemológico espelhado nas ciências naturais, que amparado no paradigma positivista, trata os

fenômenos educativos sob o viés da quantificação, mensuração e 
simplificação. Um exemplo disso é inserção das chamadas "pesquisas baseadas em evidências"1 no âmbito da pesquisa educacional, que objetivam elevar a educação ao status de saber científico, através de "provas" científicas comprovadas, derivadas de pesquisas experimentais ou quase-experimentais, por meio de experimentações controladas aleatórias.

Nessa perspectiva, a falta de tratamento adequado com o conceito e a não consulta à tradição, impelem a pesquisa educacional a uma fragilização da teoria, que, em última instância, impossibilita a pesquisa de transpor a imediatidade da realidade.

A nosso ver, uma das causas principais da fragilidade teórica dos estudos no campo educacional se deve ao que Marcuse, em um outro contexto, chamou unidimensionalização da linguagem, ou seja, a eliminação da bidimensionalidade da negatividade dialética do conceito, em favor de uma linguagem purgada do negativo, do transcendente. $\mathrm{O}$ apelo excessivo da pesquisa ao empírico, abstendo-se do contato com a tradição teórica, segue a perspectiva da linguagem unidimensional. Na exigência de soluções rápidas para os complexos problemas formativos, a pesquisa empírica deixa de lado a mediação conceitual e, assim, fica pressa a um racionalismo utilitarista, que no mais das vezes, restringe-se às soluções oriundas da quantificação e mensuração das variáveis.

Para Dalbosco (2014), a guinada apressada ao empírico faz com que este passe a ser entendido como um dado que fala por si mesmo, alheio aos fatores históricos e sociais que compõe a realidade do dado. Essa perspectiva empirista reduz a investigação da questão educacional ao ensino como procedimento pedagógico, o que impede a pesquisa de pensar as questões mais amplas do complexo processo formativo do ser humano.

Partindo da análise realizada por Dalbosco, o nosso artigo pretende rastrear este diagnóstico através de uma releitura do conceito de linguagem unidimensional em Marcuse. Nessa perspectiva, cabe questionar: de que maneira a unidimensionalização da linguagem colabora para um

\footnotetext{
${ }^{1}$ Para uma crítica ao movimento da pesquisa educacional baseada em evidências, ver o artigo de Chizzotti (2015).
} 
A unidimensionalização da linguagem e a fragilização teórica do campo investigativo educacional: desafios para a pesquisa em educação

inflacionamento do empírico na pesquisa educacional, e quais as consequências desse processo para a pesquisa? Mais ainda, como a pesquisa teórica e o pensamento conceitual podem contribuir para reverter esse quadro de simplificação da pesquisa?

$\mathrm{Na}$ concepção de Marcuse, o conceito deve ser entendido como parte de um processo altamente complexo do pensamento, em que o objeto só pode ser entendido na medida em que é reconstituído em sua condição e relação universal, transcendendo a aparência imediata. Na pesquisa educacional, o trabalho adequado do conceito e a utilização de uma linguagem intelectualizada, pautada na riqueza dos universais, permite que se ultrapasse a linguagem espoliada da comunicação cotidiana, expondo o que é constantemente suprimido no universo mutilado do unidimensional. Dessa maneira, transcende o universo simplificado do uso comum para compreender a verdadeira natureza do objeto na direção de sua realidade.

No presente ensaio, procuramos analisar a pesquisa educacional sob o olhar do conceito marcuseano de linguagem unidimensional, norteando nossa investigação em três pontos nodais. Primeiramente, procuramos trabalhar as bases da definição de linguagem unidimensional, seu funcionamento e formas de aparição nas sociedades avançadas, tendo em vista sempre a obrigatória historicidade desse conceito. A seguir, analisaremos as implicações da utilização da linguagem unidimensional no campo da pesquisa educacional, o que recai na problematização da empiria e no abandono das análises de cunho teórico, o que implica um atrelamento demasiado da pesquisa ao empírico, o enfraquecimento do caráter histórico da investigação e o arrefecimento do pensamento negativo. Na terceira parte, daremos ênfase para a necessidade de retomada dos estudos de caráter teórico, ressaltando a importância do estudo dos clássicos como obras que guardam em si a riqueza da linguagem bidimensional. Ao recuperar o diálogo com os clássicos, a pesquisa educacional tem ainda a oportunidade de incorporar toda a historicidade inerente à compreensão dos clássicos. 


\section{Linguagem unidimensional e sociedade}

Pode-se dizer que a modernidade funda-se em uma meta-narrativa que é derivada do projeto iluminista de libertar o homem da superstição através das potencialidades da razão e da ciência. Negando o pensamento prevalecente até o Renascimento de que a fé e a natureza eram forças universais, o paradigma moderno tende a basear-se em um conceito racionalista que elege o pensamento científico em detrimento do senso comum, o que resulta em uma abordagem metodológica que baliza o conhecimento através da previsão, das leis e do domínio da natureza.

Embora a quantificação positivista fosse o modelo principal a ser seguido pelas ciências naturais, não demorou muito para que a eficiência do método fosse adotada também pelas ciências humanas. Mais ainda, a necessidade de eliminação dos elementos difusos, abstratos e incertos da metafísica, da filosofia e da arte, incentivara a utilização do positivismo como meio de purgar o pensamento da crítica. Ao estudar as realidades sociais segundo o modelo da natureza e sob o aspecto da necessidade objetiva, o positivismo pregava a independência dos fatos, sendo que a argumentação deveria orientar-se para a aceitação do dado.

Nesse sentido, a filosofia positivista se esforçava para frear o processo crítico que incluía a negação filosófica dos dados, adotando a postura "positiva" de aceitação do estado de coisas. A consequência mais grave desse processo, ao ver de Marcuse, reside no fato de que ao encorajar a abdicação do pensamento frente ao imediatismo do dado, o positivismo impediu a interpretação dos fatos nas categorias de uma crítica geral do próprio elemento, e esta falta de recurso em relação ao dado constitui um vício redibitório (NICOLAS, 1971, p. 104).

Marcuse estudou a fundo as consequências do processo no qual a positivação da ciência se imiscuiu no universo da ação social. Para o filósofo, a eliminação do negativo constitui instrumento base para a criação de uma consciência feliz²: ao purgar o pensamento das contradições, bloqueia a reflexão e impõe uma postura conformista ao

\footnotetext{
${ }^{2}$ Tal conceito faz referência direta à concepção hegeliana de consciência infeliz.
} 
A unidimensionalização da linguagem e a fragilização teórica do campo investigativo educacional: desafios para a pesquisa em educação

sujeito. Ao estender-se a outros aspectos da cultura e da sociedade, a mensuração e a quantificação positivistas inserem-se também no complexo universo da comunicação em que o comportamento se expressa. A este processo, Marcuse chamou linguagem unidimensional, ou seja, a unificação e simplificação na qual se eliminam os elementos transcendentes e críticos da linguagem que permitem a negação da sociedade estabelecida.

A linguagem unidimensional atua promovendo uma autoidentificação do sujeito com o discurso difundido, convertendo esse discurso ideologicamente manipulado no principal elemento formador da subjetividade individual, gerando uma identificação imediata entre sujeito e sociedade.

Para o filósofo, o operacionalismo da linguagem unidimensional funciona como uma das novas formas de controle social que aparecem na época do capitalismo tardio. A modificação perpetrada pela unidimensionalidade abarca tanto o âmbito cotidiano do pensamento e da comunicação, quanto, de outro lado, a ciência e o ambiente acadêmico, servindo para "coordenar ideias e metas com as que são reclamadas pelo sistema prevalecente, para incluí-las no sistema e para repelir as que sejam irreconciliáveis com o sistema (MARCUSE, 1987, p. 33).

A coordenação da linguagem, dessa maneira, serve para preservar o comportamento social esperado e desejável pelo sistema. Contudo, é preciso considerar que a dinâmica de manutenção do status quo, em virtude desse fenômeno, não replica a abordagem já apresentada pelo marxismo ortodoxo. Ademais, tal abordagem nos auxilia a compreender Marcuse como membro da primeira geração da teoria crítica.

Marcuse designa esse processo como comportamento tecnológico ou "hábitos de pensar" social, já que a unidimensionalização da linguagem age diretamente na criação de um determinado modelo de comportamento que impede a tomada de consciência real das condições existenciais pela eliminação das contradições: "na expressão desses hábitos de pensar sociais, a tensão entre aparência e realidade, fato e fator, substância e atributo, tende a desaparecer" (MARCUSE, 1978, p. 93). A linguagem 
unidimensional restringe a busca de soluções além das já apresentadas sob a forma do dado, pois os elementos de autonomia, descoberta, demonstração e crítica da bidimensionalidade da linguagem recuam diante da designação, asserção e mensuração. Nesse contexto, a locução é privada das mediações que são etapas essenciais do processo de avaliação cognitiva.

$\mathrm{Na}$ forma de funcionamento dos hábitos de pensar social está a dissolução da tensão entre aparência e realidade, pela abreviação e condensação da estrutura da sentença. Um dos principais elementos dessa forma de linguagem é o operacionismo, o ato de tornar o conceito sinônimo de um conjunto de operações correspondentes, classificando no nome das coisas os indicativos do seu modo de funcionar. Dessa maneira, a palavra é abreviada a um significado único que impõe, na sua designação, o imperativo de que o comportamento não transcenda o que foi anunciado e padronizado de antemão: "a palavra se torna um clichê e, como tal, governa a palavra ou escrita; assim, a comunicação evita o desenvolvimento genuíno do significado" (MARCUSE, 1978, p. 95). A simplificação da linguagem impede, com a fixação do significado, a reflexão e a crítica.

A linguagem unidimensional possui, ademais, um caráter essencialmente ideológico: "é sistematicamente promovido pelos elaboradores da política e seus provisionadores de informação em massa" (MARCUSE, 1978, p. 34). Estes, continuadamente povoam o universo da palavra com hipóteses autovalidadoras que, a força de serem repetidas, tornam-se sentenças. Desse modo, o termo "livres" é utilizado para designar instituições que operam no mundo livre, sendo que outras formas de liberdade se tornam, por definição, anarquismo ou propaganda. Palavras como "liberdade", "igualdade" e "paz" tornam-se distintas, quando não contraditórias, segundo o conjunto de atributos que as acompanham.

No Ocidente, tais palavras estariam ligadas invariavelmente à empreendimento, livre-iniciativa e indivíduo; no Oriente a termos como operários, camponeses e abolição de classes. Nesses universos, segundo 
A unidimensionalização da linguagem e a fragilização teórica do campo investigativo educacional: desafios para a pesquisa em educação

Marcuse (1978, p. 96), a palavra se move apenas em torno de tautologias, nunca no sentido da transformação qualitativa.

Mesclada com a falsa familiaridade, resultado da repetição e da objetividade popular, a linguagem unidimensional se relaciona diretamente com o receptor, atingindo-o no âmbito informal da sala de estar. Um exemplo claro é a linguagem personalizada: o "seu" parlamentar, o "seu" jornal, a "sua" farmácia predileta. Não faz diferença se as pessoas acreditam ou não, pois o foco está em promover a autoidentificação entre os indivíduos e as funções por ele desempenhadas. Outro exemplo utilizado por Marcuse é o uso da redução hifenizada: "o pai da bomba-H", "jantar científico-militar", "bomba-limpa”. A hifenização reconcilia o irreconciliável. Sua função une os atores às ações de violência e proteção, propaganda e poder, fazendo com que somente possamos ver o homem ou a coisa em funcionamento: sujeito e ação tornam-se inseparáveis.

A importância da linguagem, da palavra, foram amplamente consideradas por Freud, tanto como meio de interpretação das forças anímicas que atuam no subconsciente, quanto como influência exercida pelo médico sobre o paciente no estado de cura. Freud falava da "magia das palavras", afirmando que "as palavras são o mediador mais importante da influência que um homem pretende exercer sobre o outro" (1996, p. 283).

Para Gadamer (1999, p. 566), expoente da hermenêutica filosófica, a linguagem é medium universal em que se realiza a própria compreensão: "todo compreender é interpretar, e todo o interpretar se desenvolve no medium de uma linguagem que pretende deixar falar o objeto e é, ao mesmo tempo, a linguagem própria do intérprete".

Nesse sentido, pode-se compreender como a simplificação do significado das palavras, a restrição da locução, podem causar modificações significativas na dinâmica da ação social, já que medeiam relações e influenciam comportamentos, provocando ações e reações nos indivíduos, que desencadeiam processos capazes de transformar a própria sociedade: "é a palavra que ordena e organiza, que induz as pessoas a fazerem as coisas, comprar e aceitar" (MARCUSE, 1978, p. 94). 


\section{Linguagem unidimensional e ciência: a restrição no universo da pesquisa}

Assim, pode-se compreender a seriedade com que o assunto da simplificação da linguagem foi tratada por Marcuse. Para ele, a linguagem unidimensional, mais do que restringir o seu significado cotidiano, vai muito além, e, por isto, pretende ampliar a linguagem já mutilada e unidimensional de uso comum para o universo rico e bidimensional da pesquisa. $\mathrm{O}$ atual modelo de pesquisa se dá pela simplificação e restrição do conceito: o conceito tende a ser absorvido pela palavra, já não carrega uma riqueza de significado e multiplicidade de interpretações, mas igualase a palavra de uso comum que só designa coisa e função.

A comunicação funcional representa apenas a camada externa do universo unidimensional no qual o homem é educado para adequar-se, para traduzir o negativo em positivo de modo a poder continuar produzindo no mundo organizacional dos negócios razoavelmente bem. Com relação à pesquisa, principalmente à dialética hegeliana que entende a contradição como mola propulsora da realidade, a coordenação unidimensional tem que ir mais a fundo e atacar as próprias bases: o pensamento conceitual.

No caso da restrição do conceito, "o que ocorre é uma devastadora redefinição do próprio pensamento, de sua função e seu conteúdo" (MARCUSE, 1978, p. 108). Se o objetivo é conseguir uma maior coordenação entre o indivíduo e a sua sociedade, a linguagem unidimensional atinge a mente onde são elaborados os próprios conceitos destinados a compreender, julgar e avaliar a realidade estabelecida. Conforme Marcuse, o que acontece é que esses conceitos são retirados da tradição intelectual em que se inseriam, e traduzidos em termos operacionais, sendo que essa tradução tem a função de reduzir a tensão entre pensamento e realidade pelo enfraquecimento do poder negativo do pensamento. Os conceitos já não visam à ausência daquilo que aparece, como no pensamento negativo, mas a aparência daquilo que está presente e que não é presença de coisa alguma (NICOLAS, 1971, p. 117). Assim, são 
A unidimensionalização da linguagem e a fragilização teórica do campo investigativo educacional: desafios para a pesquisa em educação

privados da negatividade dialética que os qualificava como imprescindíveis categorias de análise crítica.

Para Marcuse (1978, p. 109) o conceito representa sempre algo radicalmente diferente das palavras de uso comum, pois o termo "conceito" é utilizado como designação da representação mental de algo que é compreendido, entendido e conhecido como sendo resultado de um complexo processo de reflexão, não importando se esse algo for um objeto, uma situação, uma sociedade ou um conto. Existem uma clara dialeticidade e historicidade que envolve o uso do conceito, pois quando as coisas são compreendidas, tornam-se objetos do pensamento, remetendo seu conteúdo e significado a algo idêntico aos objetos reais da experiência e, ao mesmo tempo, diferente deles. Ou seja, as coisas tornam-se também resultado de um processo de reflexão que entende a coisa à luz de outros elementos que não aparecem na experiência imediata e explicam a coisa em um processo de mediação.

Dessa maneira, pode-se dizer que se o conceito jamais denota uma definição concreta e única, e que se ele é sempre abstrato e geral, assim o é porque compreende mais do que uma determinada coisa ou outra que não ela mesma. Somente dessa maneira ele pode abarcar a complexidade de ligações, possibilidades e potencialidades das coisas para além da aparência imediata:

Se o conceito de algo concreto é o produto de classificação, organização e abstração mentais, esses processos mentais levam à compreensão somente na medida em que reconstituem a determinada coisa em sua condição e relação universais, transcendendo assim a sua aparência imediata na direção de sua realidade (MARCUSE, 1978, p. 110).

Se a linguagem unidimensional bloqueia o desenvolvimento conceitual, se milita contra a abstração e a mediação, ela repele também o conteúdo histórico dos conceitos, tornando-se, dessa maneira, uma linguagem essencialmente anticrítica e antidialética. 
Como a realidade constitui-se na tensão permanente entre essência e aparência, entre o que "é" e o que "deve ser", a supressão do pensamento conceitual e, com ele, o caráter histórico das contradições, representa para Marcuse uma supressão da própria história. O que não deixa de constituir assunto político, já que é supressão do próprio passado da sociedade, assim como de seu futuro, pois esse futuro invoca a transformação qualitativa e a negação do presente (MARCUSE, 1978, p. 103). O pensamento conceitual possibilita o reconhecimento dos fatos que formam a realidade e, assim, fornece também elementos para pensar as possibilidades de transcender essa mesma realidade.

O impacto mais forte ocasionado pela linguagem unidimensional, na acepção de Marcuse, é sentido na pesquisa empírica, pois na medida em que esta se aproxima dos métodos utilizados pelas ciências naturais, tende a dar o mesmo trato ao conceito dispensado pelo quantitativo.

A redefinição do pensamento que tem por meta coordenar as operações mentais com a realidade social visa uma terapia, na qual a análise linguística alega curar o pensamento e a palavra das noções metafísicas que confundem a sentença, ou conforme Marcuse (1978, p. 163), livrar o pensamento “de 'fantasmas' de um passado menos amadurecido e menos científico que ainda assombram a mente, embora não designem e não expliquem". Como o conceito carrega um excesso de significado, tem uma natureza não-concreta e não pode ser comparado com os modelos metodológicos que se baseiam na mensuração e na quantificação.

O modelo hegemônico quantitativo-positivista, característico, sobretudo, das ciências naturais, ao ser legitimado como ideal cientificista da modernidade, teve seu modelo metodológico transposto também para as ciências humanas. Tal fato também foi sentido no campo educacional, que pôde assistir a invasão na pesquisa pelos métodos quantitativos que prometiam uma resposta eficaz e rápida aos problemas educacionais, visto o sucesso alcançado pela metodologia em outros campos do saber.

No entanto, atitudes como esta podem tornar-se amplamente problemáticas, já que, conforme Dalbosco (2014, p. 1031), ao proceder 
A unidimensionalização da linguagem e a fragilização teórica do campo investigativo educacional: desafios para a pesquisa em educação

dessa maneira, as ciências do espírito correm o risco de objetivar "aquilo que por princípio não deve ser objetivado, isto é, o próprio ser humano". A guinada apressada ao empiricismo na pesquisa educacional vem acompanhada ainda de um abandono crescente da fundamentação teórica da pesquisa, o que provoca, em última instância, o enfraquecimento das próprias pretensões de validade do conhecimento educacional (DALBOSCO, 2014, p. 1032).

O resultado desse panorama passa a ser a guinada da pesquisa educativa ao empírico como um dado que fala por si mesmo, a um simples objeto que pode ser retirado da realidade, mensurado e analisado tal qual uma informação exclusivamente quantitativa. Nesse caso, o recurso à análise conceitual, à historicidade e à dialeticidade que envolve a complexidade do objeto empírico é ignorado, e a pesquisa que pretendia compreender o intricado processo formativo não ultrapassa a descrição em meros termos reificados.

Não se trata aqui de negar o empírico ou de recair em uma filosofia pré-hegeliana com pretensão metafísica, já que Marcuse defendeu sempre a necessidade da filosofia ultrapassar os limites da especulação e transcender o idealismo para a esfera da transformação das condições objetivas da existência. Tão pouco essa crítica ao empírico deve se transformar em uma negação da consciência espontânea, pois conforme Dalbosco (2007, p. 54) é nela que "reside o pano de fundo cultural do qual brotam as construções simbólico-significativas da vida humana e social, inclusive as elaborações teórico-conceituais".

A dificuldade posta reside em problematizar uma noção de pesquisa empírica que abandona completamente os seus obrigatórios referenciais teóricos e, assim, torna-se vazia, pois já não pode contar com a mediação conceitual que permitia transcender os horizontes da prática imediata. O problema é que a partir do momento em que a pesquisa empírica abandona o recurso à teoria, ela abandona também a linguagem bidimensional do conceito, passando a orientar-se unicamente pelo uso espoliado da locução cotidiana. 
Desse modo, a pesquisa afasta-se do negativo, daquilo que é antagônico e diferente, e que não pode ser entendido em termos do uso comum. Sem a mediação do conceito, a pesquisa não dispõe dos elementos com os quais possa contrapor os objetos da realidade com a possibilidade de sua superação: o pensamento extenua-se no unidimensional, a consciência coisifica-se ao nível da quantificação geral das coisas e dos seres.

No parecer de Marcuse, a aceitação radical da pesquisa empírica viola ainda o próprio empírico, isso "porque nele fala o indivíduo mutilado, 'abstrato', que só experimenta (e expressa) aquilo que lhe é dado (dado em sentido literal), que dispõem apenas dos fatos e não dos fatores, cujo comportamento é unidimensional e manipulado" (MARCUSE, 1978, p.173). Ao renunciar ao pensamento conceitual, a pesquisa empírica tornase incapaz de compreender o objeto, porque desacredita ou traduz os conceitos que poderiam guiar um entendimento dialético da realidade. A linguagem ordinária e simples do homem comum pode ser, de fato, de importância fundamental para a pesquisa, mas somente quando ela passa pela mediação do pensamento conceitual: só assim as palavras perdem a sua aparente simplicidade e revelam aquilo que permanecia escondido na análise puramente mecânica. $\mathrm{O}$ uso adequado da terminologia na pesquisa educacional vai muito além da clarificação de interpretações: "as expressões carregam significados cuja consciência e escolha de emprego de outra expressão a partir dela representaria um passo na superação da alienação (ou cooptação) com que expressamos, pela linguagem, nosso pensamento" (GATTI, 2012, p. 16).

Pode-se dizer também, que de outro extremo, a pesquisa empírica por si só não é suficientemente racional. Isto é, a pesquisa torna-se mistificada na medida em que, abstendo-se da fundamentação teórica e do vínculo mantido com uma análise sócio-histórica, se isola do contexto verdadeiramente concreto que faz os fatos e determina a sua função. E esse contexto é muito maior do que o da sala da aula, da escola, dos setores e dos grupos que o estudo de caso atinge. É também mais real no sentido de criar e determinar os fatos investigados. 
A unidimensionalização da linguagem e a fragilização teórica do campo investigativo educacional: desafios para a pesquisa em educação

Para Marcuse, "esse contexto real no qual os sujeitos particulares obtêm sua significação real só é definível dentro de uma teoria da sociedade" (MARCUSE, 1978, p.180, grifos do autor). As determinantes que implicam na construção da realidade, dos fatos observados, não são dados imediatos de observação, mensuráveis. "Esses só se tornam dados numa análise capaz de identificar a estrutura que mantém juntas as partes e os processos da sociedade e que determina sua inter-relação" (MARCUSE, 1978, p. 180).

Conforme Marcuse (1978, p. 110) os conceitos cognitivos sempre possuem um significado transitivo, indo além da referência descritiva a determinados fatos. Isso significa que são capazes de funcionar como categorias dialéticas de análise para a pesquisa, já que transcendem a imediaticidade do dado, sem, contudo, permanecer presos a significados fixos. Os conceitos vão além de qualquer contexto especial de fatos, e em virtude de sua inerente historicidade, são capazes de transcender todo o contexto operacional. Contudo, quando a pesquisa educacional deixa de lado o trato com o conceito e o utiliza em sua dimensão operacional, acaba por enfraquecer o seu poder negativo e, com isso, a capacidade da pesquisa em ultrapassar o velo material. A retirada acrítica dos conceitos da tradição em que estavam inseridos, banaliza e simplifica o significado, reduzindo a complexidade do seu sentido a uma palavra de uso comum. São exemplos disso, a ingenuidade com que algumas pesquisas em educação utilizam conceitos complexos como pensamento crítico, formação e emancipação como sinônimos de termos de uso cotidianos ${ }^{3}$.

\footnotetext{
${ }^{3}$ Para Gatti e André “o que se encontra em muitos trabalhos são observações casuísticas, sem parâmetros teóricos ou inferências consistentes, a descrição do obvio, a elaboração pobre de observações de campo conduzidas com precariedade, análises de conteúdos realizados sem metodologia clara, incapacidade de reconstrução do dado e de percepção crítica de vieses situacionais, desconhecimento no trato da história e de estórias, precariedade na documentação e na análise documental" (2010, p. 36)
} 


\section{O compromisso da filosofia da educação e dos clássicos na pesquisa educacional}

Quando parte de uma linguagem simplificada, excluindo o vocabulário intelectual, a pesquisa se abstrai das qualidades e características que, justamente por serem outras que não as do uso comum, medeiam à construção do conhecimento com base na contradição. $\mathrm{O}$ conhecimento obtido pela via do pensamento conceitual é sempre resultado de um processo de superação do que é estabelecido através da reflexão. Dessa maneira, vai, diretamente, na contramão da afirmação de Wittgenstein de que "os problemas não são resolvidos pelo fornecimento de informação nova, mas pela rearrumação do que sempre soubemos" (apud MARCUSE, 1978, p. 169).

Nesse sentido, para que a pesquisa educacional seja capaz de superar a fragilidade epistemológica, que enfraquece as pretensões de validez do conhecimento educacional e impede o aprofundamento exigido pelas mudanças ocorridas nas sociedades complexas e plurais, torna-se urgente retomar os estudos de caráter teórico. Tendo como ponto de ancoragem o pensamento conceitual, a pesquisa em educação pode romper as fronteiras do dado imediato, compreendendo a totalidade do objeto com relação à sua inerente historicidade.

Se é necessário um retorno da análise de cunho teórico, de uma ancoragem na tradição e no conceito filosófico, tampouco, no entanto, podemos exigir uma postura da filosofia como saber fundamentador da pedagogia. Essa seria uma relação puramente assimétrica e verticalizada, na qual uma racionalidade hegemônica manteria o foco da ação e da análise, dirigindo o processo de construção do conhecimento segundo uma perspectiva de saberes fundamentadores (filosofia) e fundamentados (pedagogia) (DALBOSCO, 2007, p. 41).

Tal perspectiva, além de suprimir toda a especificidade que caracteriza os estudos do campo educacional, corre também o risco de cair no dogmatismo, na medida em que se deixa guiar por pressupostos 
A unidimensionalização da linguagem e a fragilização teórica do campo investigativo educacional: desafios para a pesquisa em educação

metodológicos e epistemológicos "de fora", ou seja, que pouco ou nada colaboram para a pesquisa educacional.

Ao resgatarmos a filosofia de Marcuse e a importância dispensada por ele à bidimensionalidade da linguagem, podemos evocar a importância do pensamento conceitual para a pesquisa em educação na perspectiva de um diálogo com a tradição, que se aproxima muito da hermenêutica gadameriana $^{4}$.

Na perspectiva hermenêutica, o diálogo com o clássico acontece numa perspectiva do zelo conceitual, isto é, a preocupação com a historicidade do texto, o uso adequado dos conceitos torna-se uma exigência primordial. Somente na medida em que ambos os lados (filosofia e educação) forem capazes de abandonar seus dogmatismos e certezas prévias, é possível levar adiante o diálogo vivo como construtor de significados. A consulta à tradição deve servir ao propósito de esclarecer os problemas contemporâneos à luz de referências teóricas e conceitos capazes de mediar uma produção de conhecimento que nasce de um todo social, cultural e histórico. Dessa maneira, a filosofia não atua como mera fornecedora de conceitos a uma ciência nascente, mas atua em parceria, em uma dinâmica que completa a pesquisa educacional.

Para Marcuse, a filosofia deveria, além de estabelecer conceitos, articulá-los com a realidade para, assim, fornecer material crítico que entre em confronto com essa mesma realidade. Seguindo essa linha, o compromisso histórico da filosofia seria mantido pelo pensamento negativo e pelo poder dos universais como instrumentos conceituais com os quais o sujeito pode confrontar a sua realidade. Mais do que representar elementos teóricos para a compreensão dos objetos do conhecimento, os universais representam categorias fundamentais com as quais é possível interferir na transformação das condições existenciais. A manutenção dos universais e de suas qualidades intraduzíveis representa a persistência da consciência infeliz, em que aquilo que "é" fica aquém e até nega aquilo que "pode ser". A linguagem bidimensional é, portanto, intraduzível em

\footnotetext{
${ }^{4} \mathrm{O}$ foco de nosso ensaio não será a hermenêutica filosófica e a pesquisa educacional. Para essa temática, ver Dalbosco, Dala Santa e Baroni (2018).
} 
termos operacionais, evoca a um só tempo, as propriedades e potencialidades do objeto pesquisado:

A diferença irredutível entre o universal e os seus particulares parece estar arraigada na experiência primária da diferença inconquistável entre potencialidade e realidade - entre duas dimensões do mesmo mundo experimentado. O universal compreende numa só ideia as possibilidades que são realizadas e, ao mesmo tempo, impedidas na realidade (MARCUSE, 1978, p. 196-197).

A simplificação dos conceitos, mais do que empobrecer a pesquisa, elimina essa dimensão tão importante da análise que é a possibilidade de vislumbrar o horizonte de possibilidades para além da realidade imediata em direção da sua superação.

Nesse aspecto, a pesquisa aproxima-se da expressão da arte, em que a transformação estética do conteúdo representa a realidade ao mesmo tempo em que a denuncia: "a transformação estética é conseguida através de uma remodelação da linguagem, da percepção e da compreensão, de modo a revelarem a essência da realidade na sua aparência: as potencialidades reprimidas do homem e da natureza" (MARCUSE, 1977, p. 21). A linguagem poética fala das coisas que são ausentes, e que mesmo assim, assediam o universo da palavra e do comportamento, ressaltando a necessidade de superação do estado de coisas em direção da realização das suas potencialidades reprimidas.

A riqueza dos universais, do pensamento conceitual como instrumentos de mediação com a realidade, pode ser apropriada pela pesquisa educacional pela via da aproximação com os clássicos, ou seja, com aquelas obras que nunca terminaram de dizer o que tinham para dizer (CALVINO, 1993, p. 11). Tanto as obras mais representativas da filosofia, quanto da arte, da literatura, souberam reter o espírito da época em que foram escritas, não só o contexto sócio-histórico, mas os grandes ideais que moviam a época. A tradição dos clássicos nos legou um manancial de conceitos, abordagens e concepções, que podem clarificar os problemas 
A unidimensionalização da linguagem e a fragilização teórica do campo investigativo educacional: desafios para a pesquisa em educação

contemporâneos, não no sentido de propor respostas rápidas que orientem a prática, mas como obras que, por sua riqueza teórica, fornecem instrumentos conceituais para a mediação com o real.

Os clássicos aparecem, portanto, como portadores dos universais enquanto instrumentos conceituais que possibilitam o entendimento das coisas particulares à luz de suas potencialidades, com uma linguagem que é, em sua essência, bidimensional. A obra Razão e revolução (1972) pode ser citada como um exemplo de como Marcuse salva a bidimensionalidade da linguagem por meio do estudo profícuo dos clássicos e de suas teorias. Nesta belíssima obra, o filósofo trabalha conceitos hegelianos, como liberdade, sujeito e espírito, mostrando como eles derivam diretamente da ideia de razão e, assim, estão ligados diretamente com a ideia concreta de liberdade e revolução.

Dalbosco (2010, p. 44) reitera a importância do estudo de autores clássicos na pesquisa educacional ao defender que "o vínculo sistemático da tradição com problemas educacionais atuais permite-lhe a abertura para novos problemas e, por conseguinte, uma reestruturação de seu próprio conteúdo". Isso é possibilitado em parte pela necessidade de compreensão da inerente historicidade do texto, ou seja, porque, para que e de que lugar escrevia o autor do texto. A partir do desvelamento do horizonte sóciohistórico em que se insere o clássico, podemos, então, nos voltar para a contemporaneidade com uma perspectiva transformada, que nos lança luz sobre o presente do qual temos acesso ao clássico.

Confrontados com a tradição, os problemas formativos apresentados pelo presente tomam uma nova roupagem e permitem uma abordagem diferente, apontando soluções alternativas que não são visíveis a partir de um olhar puramente empírico.

$\mathrm{Na}$ linguagem conceitual falada pelo clássico, é possível ainda preservar uma importante dimensão da pesquisa teórica: a lembrança. "A lembrança é um modo de dissociação dos fatos dados, um modo de 'mediação' que quebra, por alguns instantes, o poder onipresente dos fatos dados" (MARCUSE, 1978, p. 104). Como parte de uma linguagem bidimensional, a historicidade inerente aos objetos é preservada, e evoca 
novamente o terror e a esperança do passado, fazendo-os surgir na realidade sob uma forma sempre nova. É essa nova forma de aparecimento do passado à luz do presente que nos permite falar dos clássicos como obras que podem renovar a pesquisa teórica em educação, pois os clássicos falam aquela linguagem cheia de significado que milita contra o fechamento do universo da locução.

A bidimensionalidade do conceito empregado na linguagem do clássico tende a preservar os elementos do tempo e da memória, assim como a racionalidade crítica que nasce da introspecção do passado das coisas. Conforme Marcuse (1978, p. 105), o reconhecimento do passado, a lembrança evocada por ele, age contra a funcionalização do pensamento pela realidade estabelecida. Mais ainda, o pensamento sobre o passado "possibilita o desenvolvimento de conceitos que desestabilizam e transcendem o universo fechado ao compreendê-lo como universo histórico". Ou seja, ao ser confrontado com a realidade imediata, o pensamento torna-se essencialmente consciência histórica. "A mediação do passado com o presente descobre os fatores que fizeram os fatos, que determinaram o estilo de vida, que estabeleceram os senhores e os servos; projeta os limites e as alternativas" (MARCUSE, 1978, p. 105).

Na medida em que Marx e Hegel associavam o conceito à história e ao devir, pode-se apreender a importância da mediação com o passado para Marcuse. De fato, a recordação permite um distanciamento em relação àquilo que é dado, é intrusão do universal no particular, é local do terror e da esperança, dos anseios e das aspirações. É aquilo que subverte o presente e o faz explodir.

Como representante da bidimensionalidade da linguagem, os clássicos permanecem como obras de consulta obrigatória para toda a pesquisa que deseja compreender a realidade atual sob a perspectiva amplificada do pensamento conceitual. "É clássico aquilo que permanece como rumor mesmo onde predomina a atualidade mais incompatível" (CALVINO, 1993, p. 15).

Ao aproximar-se da tradição, a pesquisa educacional pode repensar o seu objeto de estudo através da mediação dos conceitos, que são também 
A unidimensionalização da linguagem e a fragilização teórica do campo investigativo educacional: desafios para a pesquisa em educação

essencialmente parte de uma consciência histórica. Assim, a pesquisa pode transcender a mera matriz pragmática e empírica do imediato, para abordar o objeto a partir de um olhar amplo enraizado no horizonte histórico, e que por ser assim, pode também vislumbrar alternativas para o presente e o futuro.

\section{Considerações finais}

Ao contrário do que se quer fazer crer, a teoria não representa uma dimensão separada e irreconciliável com a empiria, já que a teoria possui uma capacidade antecipadora, crítica, remontando seus conceitos nas manifestações imediatas do real, e apontando os rumos do desenrolar histórico. Sendo assim, pode-se compreender que a pesquisa em educação que realmente deseje ultrapassar a condição de puramente descritiva, envolvendo a totalidade das condições que formam o objeto de estudo da pesquisa educacional, ou seja, o próprio processo formativo, precisa necessariamente amparar-se nas matrizes sólidas da tradição teórica. Somente dessa maneira poderá enfrentar a predominância irrefletida do empírico e da fragilidade teórica, recolocando como exigência para a pesquisa educacional a retomada de questões mais amplas e profundas, diretamente relacionadas com o processo formativo do ser humano como um todo.

Nesse sentido, entendemos que é urgente e necessário a superação da linguagem unidimensional adotada pela pesquisa empírica, e uma retomada da tradição pela via dos clássicos, já que neles conserva-se inalterada toda a bidimensionalidade do pensamento conceitual. É preciso ressaltar que o que está em jogo neste caso não é meramente a defesa da pesquisa teórica frente à empiria, mas sim a necessidade de falar e pensar em outros termos que não os do uso comum, e que são significativos, racionais e válidos precisamente por serem outros termos. Eles carregam a negatividade dialética que contradiz os fatos dados e induzem a uma interpretação diferente daquela imposta pela quantificação. 
De fato, ao ultrapassar o uso comum da palavra e pautar-se na tradição e no conceito, a pesquisa educacional consegue mediar a construção do conhecimento em parâmetros teóricos sólidos com os quais pode ultrapassar a linha da realidade imediata.

O pensamento de Marcuse sempre esteve comprometido com a prerrogativa de que a filosofia deve assumir o seu papel histórico, e isso implica justamente a postura contrária àquela assumida pela filosofia da linguagem, que não pretende interferir na realidade humana, nem na esfera da linguagem. Esta seria uma filosofia descritiva, que não propõem teorias e suspende o juízo, uma postura que se aproxima perigosamente da empirização e quantificação que vêm se inserindo na pesquisa educacional.

Tanto a filosofia quanto a pesquisa educacional, diferentemente das ciências naturais, implicam juízos e invocam julgamentos sobre a esfera social, política, moral, estética e ética. Para tanto, devem ter em mente que somente ao incorporar aqueles âmbitos do pensamento classificados como negativos, metafísicos e transcendentes podem superar o cientificismo e o positivismo, colocando novamente em pauta uma pesquisa que esteja realmente voltada para a transformação da realidade estabelecida.

\section{Referências}

CALVINO, Í. Por que ler os clássicos. Trad. Nilson Moulin. São Paulo: Companhia das Letras, 1993.

CHIZZOTTI, A. A pesquisa educacional e o movimento "pesquisas científicas baseadas em evidencias". Práxis Educativa, Ponta Grossa, v. $10, \quad$ n. $2, \quad$ jul./dez. 2015, p. 325-338. https://doi.org/10.5212/PraxEduc.v.10i2.0003

DALBOSCO, C. A. Pedagogia filosófica: cercanias de um diálogo. São Paulo: Paulinas 2007. 
A unidimensionalização da linguagem e a fragilização teórica do campo investigativo educacional: desafios para a pesquisa em educação

. Natureza da pesquisa em educação: abrindo um leque de alguns problemas. In: HENNING, Leoni M. P. (org.). Pesquisa, ensino e extensão no campo filosófico-educacional: possibilidades presentes no contexto universitário. Londrina: EDUEL, 2010, p. 41-66.

- Pesquisa educacional e experiência humana na perspectiva hermenêutica. Cadernos de Pesquisa, v.44, n.154, p.1028-1051, out./dez. 2014. https://doi.org/10.1590/198053142820

DALBOSCO, C. A.; DALA SANTA, F.; BARONI, V. A hermenêutica enquanto diálogo vivo: contribuições para o campo da pesquisa educacional. Educação, Porto Alegre, v. 41, n. 1, p. 145-153, jan./abr. 2018. https://doi.org/10.15448/1981-2582.2018.1.24967

FREUD, S. Tratamento psíquico (ou anímico) (1905). In: __. Um caso de histeria, três ensaios sobre a sexualidade e outros trabalhos (19011905). Edição Standard brasileira das obras psicológicas completas de Sigmund Freud. Vol VII. Rio de Janeiro: Imago, 1996.

GADAMER, H. Verdade e método: traços fundamentais de uma hermenêutica filosófica. Petrópolis, RJ: Vozes, 1999.

GATTI, B. A construção metodológica da pesquisa em educação: desafios. RBPAE, Porto Alegre, v. 28, n. 1, p. 13-34, 2012.

GATTI, B. A.; ANDRE, M.. A Relevância dos Métodos de Pesquisa Qualitativa em Educação no Brasil. In: WELLER ,W.; PFAFF, N. (Orgs.). Metodologias da pesquisa qualitativa em Educação: Teoria e Prática. Petrópolis: VOZES, 2010.

HEGEL, G. W. F. Fenomenologia do espírito. Parte I. Trad. Paulo Meneses. 2 ed. Petrópolis: Vozes, 1992.

MARCUSE, H. Razón y revolución: Hegel y el surgimiento de la teoría social. Barcelona: Atalaya, 1972. . A dimensão estética. Lisboa: Martins Fontes, 1977. 
A ideologia da sociedade industrial: o homem unidimensional. Trad. Giasone Rebuá. $6^{\text {a }}$ ed. Rio de Janeiro: Zahar, 1978.

Teoría y praxis. In: . Calas en nuestro tiempo. Barcelona: Icaria, 1983.

NICOLAS, A. Marcuse ou a busca de um universo transprometeico. Trad. de Franco de Sousa. Lisboa: Estúdios Cor, 1971.

OLIVEIRA, R. de. O papel da filosofia na teoria crítica de Herbert Marcuse. São Paulo: Editora Unesp, 2012.

Data de registro: $31 / 07 / 2019$

Data de aceite: 30/10/2019 